Document downloaded from:

http://hdl.handle.net/10251/121112

This paper must be cited as:

Pardo Picazo, MA.; Manzano Juarez, J.; Valdes-Abellan, J.; Cobacho Jordán, R. (2019). Standalone direct pumping photovoltaic system or energy storage in batteries for supplying irrigation networks. Cost analysis. The Science of The Total Environment. 673:821-830. https://doi.org/10.1016/j.scitotenv.2019.04.050

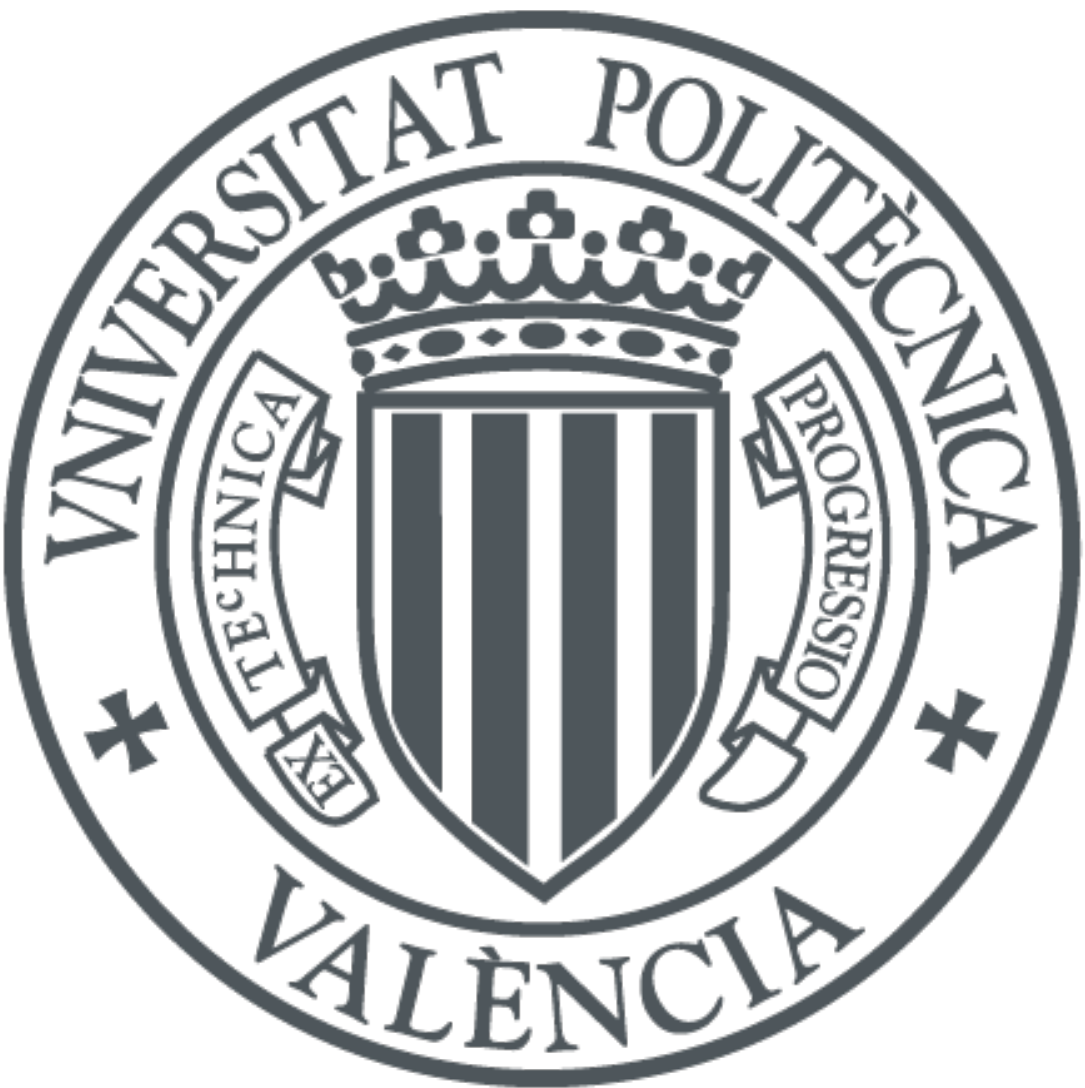

The final publication is available at

http://doi.org/10.1016/j.scitotenv.2019.04.050

Copyright Elsevier

Additional Information 


\title{
Standalone direct pumping photovoltaic system or energy storage in batteries for supplying irrigation networks. Cost analysis.
}

\author{
Pardo, M.A.a, Manzano, J.b, Valdés-Abellán, Ja a and Cobacho, R.c \\ a Department of Civil Engineering, University of Alicante, Alicante, Spain. mpardo@ua.es \\ ${ }^{b}$ Dept. Ingeniera Rural y Agroalimentaria, Universitat Politècnica de València, Valencia, Spain. \\ c ITA, Dept. Hydraulic and Environmental Engineering, Universitat Politècnica de València,
}

\begin{abstract}
Solar photovoltaic systems have become one of the most popular topics in the water management industry. Moreover, irrigation networks are water- and energy-hungry, and utility managers are likely to adapt water consumption (and consequently energy demand) to the hours in which there is energy availability. In countries such as Spain (with high irradiance values), solar energy is an available green alternative characterised by zero electricity costs and significantly lower environmental impact. In this work, several types of irrigation scheduled programmes (according to different irrigation sectors) that minimise the number of photovoltaic solar panels to be installed are studied; moreover, the effects of the variable costs linked to energy (energy and emissions costs) are presented. Finally, the effect of incorporating batteries for storing energy to protect the system against emergencies, such as unfavourable weather, is proposed. The irrigation hours available to satisfy water demands are limited by sunlight; they are also limited by the condition that the irrigation schedule type has to be rigid (predetermined rotation) and that the pressure at any node has to be above minimum pressure required by standards. A real case study is performed, and the results obtained demonstrate that there is no universal solution; this is because the portfolio of alternatives is based on
\end{abstract}


27 investments for purchasing equipment at present and also on future energy savings (revenues).

28 Apart from these two values, there is an economic value (equivalent discontinuous discount 29 rate), which also influences the final results.

\section{KEYWORDS}

Cost Analysis, Batteries, Photovoltaic, energy audit, rigid scheduled irrigation

\section{INTRODUCTION}

The water consumption in 2014 was estimated to be 4,000 billion $\mathrm{m}^{2}$ (IEA, 2016). Over the next 25 years, water withdrawals are likely to increase by $70 \%$ as a consequence of water

37 demands for food production (Alexandratos and Bruinsma, 2012). Moreover, it has been 38 estimated to be feasible to supply adequate food for $50 \%$ more population on earth (Pfister et 39 al., 2011).

The International Energy Agency (IEA, 2016) quantified the energy consumed in the water sector as $4 \%$ of the global electricity consumption. This energy consumption is projected to be more than two times over the period to 2040. The European Commission (EC) emphasises the Pathways for the transition to a net-zero greenhouse gas emissions economy and strategic

44 priorities (EC, 2018). This document highlights the need to maximise the deployment of 45 renewables and the use of electricity to completely decarbonise Europe's energy supply; 46 furthermore, it underlines Europe's dependence on oil and gas (which in 2018 represented $4755 \%$ of the energy demand) and the target for the year 2050 (to decrease to $20 \%$ of the total 48 energy demand).

49 As irrigated agriculture is the world's largest water consumer (85\% of global water 
networks represents a challenge for utility managers. In this scenario, wherein the anthropic

52 pressure generates significant consequences in the environment, solar energy emerges as a

53 'green' alternative because of the reduction in both energy consumption and emissions to the

54 environment. The reductions in the production costs of PV arrays (30-60\% in 10 years; Closas and Rap, 2016) in conjunction with the increasing oil prices have endeared this technology to decision-makers and practitioners (Bloomberg, 2016; Nederstigt and Bom, 2014). been used in numerous regions of the world, such as the U.S.A., (Clark and Vick, 2002), India (Pande et al.; 2003) and Turkey (Senol et. al., 2012). There are also certain experiences in the South of Spain (Reca, 2006; Tarjuelo et. al., 2015), a region with high potential because of its high irradiation levels. The key advantage of incorporating PV technology in irrigation is the reduction in grid energy consumption (Chandel et. al., 2015; Hadj Arab et. al., 1999) and its related environmental benefits (Todde et. al., 2019). solved the problems arising from clouds passing over the generator (Narvarte et al., 2018); in consumption, in a pressurised irrigation network has been developed (Pardo et al., 2018). It

72 enables utility managers to regulate energy demands by opening and closing hydrants and/or 73 subunits. Thereby, the energy produced by PV panels matches the energy required by crops. 74 However, there are two limitations of this study: first, it can be applied only with the aid of a 
75 calibrated hydraulic model (EPAnet, WDNetXL, Infoworks, etc.); secondly, the irrigation

76 schedule must be rigid rotation scheduled irrigation (Repogle and Gordon, 2007), which

77 involves high investments in the automation of hydraulic devices.

78 In this study, a different set of alternatives for irrigation networks management are 79 assessed, moreover, advancing beyond all the above mentioned references, the additional 80 alternative based on batteries energy storage will also be included. This is a key practical issue 81 because batteries can be an effective option for daily ordinary use, without being limited to 82 emergency situations; energy can be stored at peak hours and released during other periods.

83 The present energy supply situation, in which pumps are continuously fed from the 84 electricity network, is named as the Zero-Case. All the other feasible alternatives based on solar 85 PV technology for pump driving and/or based on different scheduling methods are compared 86 to it. According to the tool developed, the number of PV panels (Pardo et al., 2018) and the 87 energy savings are calculated in each case. UAEnergy is a freely-available application 88 (https://bit.ly/2FbNqdr), developed for calculating the monthly energy consumption (and the 89 shaft work consumed by pumps) in irrigation networks (Pardo et al., 2013). In order to enable 90 comparison, water consumption and fixed are similar for all the alternatives considered. The 91 variable costs of energy and the environmental costs (carbon credits, tons of $\mathrm{CO}_{2}$ ) represent 92 future revenues (to be paid in future). Finally, the alternatives are prioritised based on 93 economic criteria, so that the time period for complete cost-recovery (payback period) is 94 minimised.

95 The remaining part of this paper is organised as follows: Sections 2.1 and 2.2 describe the 96 infrastructure and hydraulic constraints. Section 2.3 presents the methodology for calculating 97 the number of segments into which the network has to be divided in order to manage the rigid 98 rotation scheduled programme for irrigation. The variable costs of energy are described in 
section 2.4, and the economic prioritisation is presented in Section 2.5. Section 3 describes the process for calculating the payback periods for the discrete alternatives that utility managers and decision-makers have to encounter while analysing the conversion into a standalone direct pumping photovoltaic irrigation network. A real case study is presented in Section 4; the input data is collected in Section 4.1, and the step-by-step results are presented in Sections 4.2-4.7.

\section{MATERIAL AND METHODS}

\subsection{Upper and lower network flowrate thresholds (infrastructure} constraints).

The utility manager operates a water pressurised irrigation network; the network was dimensioned for delivering water for $18 \mathrm{~h}$ to exploit the low electricity tariffs at night. When solar irradiance produces energy using the PV arrays for supplying to the direct drive pump, the irrigation time decreases. In local Mediterranean conditions, the number of hours in which photovoltaic energy is produced can be $9 \mathrm{~h}$.

..

As the irrigation time is lower, higher flow rates, and consequently higher headlosses owing to friction in the pipes are likely. In this approach, two values appear in the simulation of each water irrigation network. The first is called lower networks flowrate threshold $\left(Q_{\text {low,th }}\right)$ and represents the minimum injected flow (for the combinations arising with the opening and closing valves); it does not satisfy the pressure requirements at each node and at each time (for lower flow rates the network always satisfies the pressure standards). Meanwhile, the second is called upper network flowrate threshold $\left(Q_{u p, t h}\right)$; it is the highest value in which there is a combination that maintains the pressure above the standards (higher flowrates do not 
123 satisfy the pressure at any time and at each node). These parameters are of paramount

124 importance while selecting the number of segments (a segment a group of consumption nodes)

125 that can be opened simultaneously.

126 This flowrate threshold depends on the network layout, diameters, pipe materials, 127 lengths and the flow delivered to plots (which is obtained respect to the irrigated area and the 128 number and type of emitters). The water demand requirements by crops is calculated by 129 considering this flow rate delivered to plots and the irrigation time per hydrant. (or subunit).

130 All these irrigation pressurised network features can be integrated into a hydraulic 131 simulation software such as EPAnet (Rossman, 2000). Multiple scenarios can be simulated. 132 Moreover, using UAEnergy (an interface developed with Matlab software (Pardo et al., 2019), 133 with which the shaft work in pumps can be calculated (Pardo et al., 2013)), the minimum 134 pressure at each node and at each time of the simulation period and the thresholds are 135 determined and presented here. Another constraint (availability flowrate) should also be considered because this represents the maximum flowrate that can be delivered for certain other limitations (i.e. if the network is supplied by groundwater, it could be the maximum flowrate that can be extracted

141 from the aquifer). If the availability flowrate threshold is higher than the injected flow, there is 142 no limitation in our optimisation problem; otherwise, it should be considered in the hydraulic 143 analysis (the minimum value between the available flowrate and network flowrate will be the 144 maximum flow rate injected). This parameter and the two thresholds described above are 145 dependent on the installation (not modifiable by managers). 


\subsection{Number of segments that can operate simultaneously}

As the daily water demand in the network is specified $\left(Q_{i n j}\right)$ (after performing the

149 hydraulic analysis and considering each consumption nodes demanding water simultaneously),

150 the number of segments $\left(n_{\text {sect }}\right.$; a natural number between one and $n^{*}$ ) into which the manager

151 divides the irrigation schedule can be selected. By considering a perfect balance while selecting

152 the consumption nodes to be opened/closed, the flowrate injected at each segment is calculated

153 as follows:

154

$$
Q_{\text {sec }}=\frac{Q_{\text {inj }}}{n_{\text {sect }}}
$$

This value of flowrate $Q_{\text {sec }}$ (Eq. 1) involves a number of segments that may operate 156 simultaneously $\left(n_{\text {sim }}\right)$ as illustrated in Eq. 2:

$$
n_{\text {sim }}=\left\{\begin{array}{cc}
\text { floor }\left(\frac{Q_{u p, t h}}{Q_{\text {sec }}}\right) & \text { If } Q_{\text {sec }}<\left(Q_{\text {low }, t h}\right) \\
1 & \text { If }\left(Q_{\text {low }, t h}\right)<Q_{\text {sec }}<\left(Q_{u p, t h}\right) \\
0 & \text { If } Q_{\text {sec }}>\left(Q_{\text {up }, t h}\right)
\end{array}\right.
$$

In case $2 \mathrm{a}$ ), as $Q_{\text {sec }}$ is lower than the lower threshold, the number of segments that can

159 work simultaneously will be $n_{\text {sim }}=$ floor $\left(\frac{Q_{u p, t h}}{Q_{s e c}}\right)$. In case $2 \mathrm{~b}$ ), only one segment may deliver 160 water to crops simultaneously; moreover, in case 2c), as $Q_{s e c}$ is larger than the upper 161 threshold, pressure requirements are not satisfied in any of the cases, and $n_{\text {sect }}$ should be 162 increased.

163 The methodology for calculating the number of PV panels (Pardo et al., 2018) revealed 164 that an irrigation schedule is more energy efficient (fewer PV arrays are required) when higher 165 injected flowrates (higher values of $n_{\text {sim }} \times Q_{s e c}$ ) satisfy the pressure requirements. As 166 commented before, the irrigation time has now been reduced by solar constraints $\left(D_{i r r}\right.$, 167 generally up to 9 h, Eq. 3); moreover, the total irrigation time ( $T_{i r r}$ ) has also been defined with 
regard to the crops' water requirements. With several potential values of $n_{\text {sect }}$ and $n_{\text {sim }}$, the

169 system has to satisfy the final constraint:

$$
D_{i r r} \geq T_{i r r} * \frac{n_{\text {sim }}}{n_{\text {sec }}}
$$

If this inequality is not satisfied, the photovoltaic system will not satisfy the requirement,

173 and the problem does not have any solution. For example, being an irrigation network with $9 \mathrm{~h}$ 174 of irrigation time, the number of segments is three, one out of which may operate 175 simultaneously; the total irrigation time will be $T_{i r r} \leq 3 \mathrm{~h}$ in order to feed the direct drive pump 176 with energy produced by the PV systems.

\subsection{Variable costs linked to energy}

In order to compare the benefits of converting the irrigation pressurised network into a standalone direct pumping photovoltaic system, the water consumption (environmental costs of water, social costs, etc) and fixed costs (the utility's structure, asset amortisation, etc.) of water should be equal. According to the cost structure (Cabrera et al., 2013), the variable cost

182 of water is likely to depend on the resource, energy and effective life of the infrastructure; only the second term is relevant in this approach. This refers to the variable energy cost of operation and maintenance (energy cost linked to pumping, treatment and transport; it is proportional to

187 greenhouse gas emissions (carbon credits; tons of $\mathrm{CO}_{2}$ ) are also calculated.

\subsection{Economic prioritisation of the alternatives}

As the utility manager is considering the alternative of implementing a standalone direct

191 pumping photovoltaic system, ceratin equipments is to be purchased at the present time: the 
192 cost of PV panels, electrical devices, removal of shrubs from the ground, health and safety at 193 work during the installation of the new panels and solid waste management. Meanwhile, the 194 economic savings from reduced energy consumption will be periodically obtained (a 195 cumulative cost to be paid monthly).

196 In order to enable comparison, all the costs should be expressed in monetary units at the 197 present time using the equivalent continuous discount rate, $r$ (Kleiner and Rajani, 2001; Shamir 198 and Howard, 1979). $r$ represents the return that could be earned per unit of time on 199 an investment with similar risk.

200 With these investments and future revenues, the objective function to maximise from the 201 present time ( $t_{\mathrm{p}}$ ) to the time $t$ can be expressed as the net present value (NPV) (Eq. 4):

$$
N P V=\left[-I_{0}+\int_{t p}^{t}\left(C_{E N}+\left(C_{E N V} * E_{p}\right)\right) \cdot e^{-r t} d t\right]=\left[-I_{0}+\int_{t p}^{t} S_{i} \cdot e^{-r t} d t\right]
$$

where $I_{0}$ is the investment performed in year zero, and $S_{i}$ are the monthly economic savings it can be calculated with the energy costs $\left(C_{E N}\right)$ and environmental cost $\left(C_{E N V}\right)$ which is 205 proportional to the energy consumed by the pump ( $\left.E_{P}\right)$ ). Equating the derivative of Eq. 4 to 206 zero, the payback period of the investment (Eq. 5) is calculated as

$$
T_{i}=\frac{-1}{r} \cdot \ln \left(1-\frac{r \cdot I_{o}}{S_{i}}\right)
$$

208 where $T_{i}$ (years) is the payback period; it is to be minimised as lower values involve higher 209 energy savings, and thus higher revenues, per monetary unit invested to buy equipment (PV 210 panels). This value represents the parameter to be minimised when prioritising the alternatives 211 in this optimisation problem.

212 Finally, if an alternative considers certain other investments in certain other years (as 213 will be required in the numerical example), $I_{0}$ should be modified considering these options. 


\section{OPTIMISATION PROBLEM}

The process to select the best alternative is described in this section and in Figure 1. The

217 input data required to execute the model and the calculation process are described here

218 (Sections 3.1 and 3.2, respectively). The parameter to be minimised is the payback period $T_{i}$

219 (years) (Eq. 5), a value that considers the future revenues obtained by performing the present 220 investment.

\subsection{Input data}

222 executing using UAEnergy and a software such as Matlab.

Step 2: The availability flowrate should be assessed. If this parameter is higher than the upper threshold, the process may continue to the next step; otherwise, this upper threshold should be equal to the availability flowrate. Each alternative involves different values of investments and savings. Moreover, a few

234 alternatives including the use of batteries are also incorporated to the analysis in this step. are selected as the best alternative.

\section{Numerical example}


To illustrate the proposed methodology, a real case study has been previously presented

240 (Pardo et al., 2018): the branched irrigation network (Albamix network) located in the

241 Mediterranean region of Spain. It supplies water to 167.7 ha wherein different varieties of

242 citrus orchards are cultivated., The general planting pattern is $5 \times 4 \mathrm{~m}$ per tree. The network is

243 compounded by 131 pipes and 132 nodes, 98 of them are consumption nodes supplying water

244 to plots. The total length of the network is $4.05 \mathrm{~km}$. The pipe material is PVC, and the pipe

245 roughness of the aged pipes is $0.02 \mathrm{~mm}$ (a common value in water irrigation networks

246 according to Mc Govern, 2011). The minimum service pressure required is

$247\left(\frac{P}{\gamma}\right)_{\text {threshold }}=25 \mathrm{~m}$. w. c. The data required to calculate the irradiance curves are illustrated

248 in Pardo et al. (2018). This network was originally designed for 18-h irrigation periods.

249 Therefore, in the Zero-Scenario (current state), irrigation is performed for 18 hours at night, to

250 exploit the low energy prices because the pumps are supplied by electricity grids.

251 Scenarios 1A, 2A and 3A (Table 1) are defined depending on the number of segments into

252 which the entire irrigation network is divided: five, seven and ten, respectively $\left(n_{\text {sect }}=5,7\right.$ and $25310)$.

254 In all of these scenarios, irrigation lasts for $9 \mathrm{~h}(7: 30-16: 30 \mathrm{~h})$, and direct pumping is 255 supplied with PV energy. Segments have been grouped under the criteria of uniformity of 256 pressure and flow (Table 2) at each consumption node. For each of these three scenarios, an 257 additional battery can be considered. In this case, the three alternative scenarios $1 \mathrm{~B}, 2 \mathrm{~B}$ and $3 \mathrm{~B}$ 258 arise. The battery would enable energy storage during peak production hours for use during 259 low radiation hours. The estimated service life of the batteries and PV arrays are five and 25 260 years, respectively. Monthly water demands in the Albamix network have been obtained by 261 combining the meteorological information and crop evapotranspiration for the Penman262 Monteith method, from the past 13 years (2005-2017). Regional guidelines (Castel, 2002) have 
263 been followed to calibrate the crop coefficients. The resulting monthly average water

264 requirements vary from $18.58 \mathrm{~L} / \mathrm{m}^{2}$ in January to $116.96 \mathrm{~L} / \mathrm{m}^{2}$ in July. These demands are

265 converted into hours of irrigation per month $\left(T_{i r r}\right)$ (Table 2). Because of the sunlight in that

266 latitude, the daily irrigation time $D_{i r r}$ is $9 \mathrm{~h}$. It is observed that the highest water demands occur

267 in July, the month with the highest values of irradiance and of energy production by PV arrays

268 (Pardo et al., 2018; Duffie and Beckman, 2013).

269 Finally, the aquifer that supplies water to the network permits steady flow rate values of 270 approximately $200 \mathrm{~L} / \mathrm{s}$ during $10 \mathrm{~h}$. In contrast to the head losses constraint imposed by the 271 network, the available flow rates will not be an actual constraint in many of the situations 272 analysed.

273

$274 \quad$ 4.1. Input data for Albamix network

275 The investment required for installing the PV panels depends on the number of segments 276 in each scenario. In particular, 376736 EUR, 283083 EUR and 284351 EUR are the amounts 277 required for $n_{\text {sect }}=5,7$ and 10, respectively. The area of each PV panel in this study is $1.6 \mathrm{~m}^{2}$. 278 Certain additional information is presented at Table 3.

279 Here, $\beta$ is the angle of inclination, in radians, of the photovoltaic panels; $I_{S C}$ is the solar 280 constant $\left(1367 \mathrm{~W} \mathrm{~m}^{-2}\right) ; I_{S T C}$ is the irradiance under standard conditions $\left(1000 \mathrm{~W} \mathrm{~m}^{-2}\right) ; d$ is the 281 cell's performance decay coefficient owing to temperature increase $\left(0.004^{\circ} \mathrm{C}^{-1}\right)$; $\mathrm{H}$ is the global 282 irradiance on horizontal surface $\left(\mathrm{kWh} \mathrm{m}^{-2}\right) ; T_{S T C}$ is the cell temperature under standard test 283 conditions $\left(25^{\circ} \mathrm{C}\right) ; T_{\text {avg }}$ is the monthly average temperature $\left({ }^{\circ} \mathrm{C}\right) ; \varphi$ is the latitude angle in 284 radians (positive to the North); $n$ is the day which better represent monthly irradiation (Duffie 285 and Beckman, 2013), a given value; $\rho$ is the albedo (-); PP is the peak power generated by the 
286 PV modules, in $W ; \eta_{p}$ is the pump efficiency $(-) ; \eta_{a m}$ is the asynchronous motor efficiency (-) 287 and $\eta_{f c}$ is the converter efficiency $(-)$. The monthly irradiation curves for the Albamix network are identical to those already calculated in Pardo et. al., (2018). In particular, the irradiation curve in July is:

$$
E_{a v}\left(\frac{W}{m^{2}}\right)=-1.08 \times 10^{15} \times x^{5}+0.08 \times x^{4}-3.80 \times x^{3}+59.44 \times x^{2}-332.72 \times x
$$

$$
+605.41
$$

where $\mathrm{x}$ is the hour of the day, in hours.

293 The integration of this parabola between the $7.5^{\text {th }}$ and $16.5^{\text {th }}$ hours, the time during which solar 294 irradiation can be profitably converted into electricity, results in $1766 \mathrm{~W} / \mathrm{m}^{2}$. Considering the 295 pump, asynchronous motor and converter efficiencies, the net energy transferred to water per 296 PV panel per hour of the day can be calculated as shown in Figure 2. The energy produced per 297 PV panel (whose area is $1.6 \mathrm{~m}^{2}$ ) is calculated by integrating this parabola; its value is equal to $2981210.5 \mathrm{Wh}$. The cost of the batteries is $32895 \mathrm{EUR}$; their nominal capacity is $50000 \mathrm{kWh}$.

299 The savings thus obtained are the variable energy costs linked to the water distribution 300 in the Albamix irrigation network at zero-scenario, for the six scenarios analysed. These savings 301 have been calculated considering 3.0 Tariff. In Spain, the electricity tariff is compounded by 302 three elements: the price of the power installed (measured in $\mathrm{kW}$ ), price of the (active) energy 303 consumed (measured in kVArh) and price of the reactive energy (measured in kWArh). The 304 selected tariff comprises three periods each day: the peak period extends for $4 \mathrm{~h}$ (prices are $30540.72 \mathrm{EUR} / \mathrm{kW}, 0.018762 \mathrm{EUR} / \mathrm{kWh}$ and $0.062332 \mathrm{EUR} / \mathrm{kVAr}$ ), plain period extends for $12 \mathrm{~h}$ 306 (24.43733 EUR/kW and 0.012575 EUR/kWh and 0.062332 EUR/kVAr) and low period extends 307 for $8 \mathrm{~h}$ (16.29 EUR/kW and $0.00467 \mathrm{EUR} / \mathrm{kWh}$ and $0 \mathrm{EUR} / \mathrm{kVAr}$ ). In order to maximise the 308 practicality of the study, a 5\% tax (direct electricity tax) is added to the sum of the three 309 previous costs; moreover, $50 \mathrm{EUR} /$ month (for renting the electricity meters) and the final VAT 
310 (21\%, the general value in Spain; BOE, 2012) are added for obtaining the operation and 311 management costs.

\section{4.2. Network flowrate threshold}

In order to calculate the relationship between the minimum pressure and inlet flow, 20000 simulations are performed. In each of the simulations, several hydrants and subunits are opened simultaneous and randomly. The inlet flow values thus obtained vary from 1.1 to

$317256.6 \mathrm{~L} / \mathrm{s}$ (the number of consumption nodes opened ranging from one to 73). The minimum 318 pressure registered for these 20000 simulations range between 6.35 and 42.13 m.w.c. (Figure 319 3). For the simulation stage, 16181 out of 20000 simulations displayed successful water 320 delivery above pressure conditions, 3815 out of 20000 displayed certain node pressures below 321 the standards and four simulations were discarded because of negative pressures. imply a minimum pressure below 25 m.w.c.) and the upper network flowrate threshold is 324 194.9 L/s (the maximum flowrate for which pressure standards can be satisfied). than the upper maximum threshold flowrate, the number of segments estimated by the utility manager implies specified values of inlet flow per sector (Eq. 1; Table 4). The availability

331 flowrate $(200 \mathrm{~L} / \mathrm{s})$ represents a limitation when segmentation into two segments is considered;

332 this is because the network inlet flowrate $\left(Q_{\sec }=212.2 \mathrm{~L} / \mathrm{s}\right)$ is higher than the upper maximum 333 flowrate (the minimum pressure would be below the standards (Figure 3)). 
The number of segments $\left(n_{\text {sim }}\right)$ that may operate simultaneously are calculated by Eq. 2 ,.

Finally, the new scenarios should satisfy the final requirement expressed by Eq. 3; in case the irrigation time is likely to satisfy the requirement, 'YES' is displayed in the fifth column (right column in Table 4). If the number of segments is three, the inlet flow per segment supplied is 141.47 L/s (Eq. 1); this is lower than the network flowrate threshold (Figure 3); moreover, according to Eq. 2, only one segment can be opened simultaneously (Table 4). As aforementioned, the irrigation time $\left(T_{i r r}\right)$ is $3.33 \mathrm{~h}=200 \mathrm{~min}$; the profitable time to convert solar energy into pump shaft work is $D_{i r r}=9 \mathrm{~h}=540 \mathrm{~min}$. Therefore, for those three segments (Eq. 3), $9.99 \mathrm{~h}=600 \mathrm{~min}$ should be satisfied to fulfil the requirements, and only $9 \mathrm{~h}=540 \mathrm{~min}$ would be available. In conclusion, it would not be feasible to use this segmentation in this particular case.

Based on these numbers, the most appropriate number of segments is that in which there is an increase in the number of simultaneous segments supplied. Therefore, five, seven and ten segments are the aforementioned candidates (Table 1).

Figure 4 has been obtained for the 4460 simulations (out of the 20000 simulations performed in the network used for Figure 3); it oscillates between the upper and lower threshold (152.5 and 194.9 L/s.). It is observed that 3988 out of these 4460 combinations satisfy the standards, whereas 472 do not. Therefore, an empirical distribution function has been formulated to obtain the probability of occurrence of an event. This is a step function that jumps up by $1 / \mathrm{n}$ at each of the 472 values in which the random simulation does not satisfy the pressure requirements. The result at any specified value of the measured variable is the fraction of observations of that measured variable that are less than or equal to the specified value.

According to the numbers for five segments, presented in Table 1 and Table 4, two can be delivered simultaneously (because each segment delivers $85.4 \mathrm{~L} / \mathrm{s}$; this is converted into 85.4 
$358 \times 2=170.8 \mathrm{~L} / \mathrm{s}$, with pressures above 25 m.w.c. and 99.78\% probability; Figure 4). For seven

359 segments, three can operate simultaneously $(3 \times 60=180 \mathrm{~L} / \mathrm{s}$; moreover, there can be certain

360 alternatives that can satisfy the pressure requirements with 98.31\% probability; Figure 4).

361 Finally, for ten segments, four segments can be opened simultaneously because the least

362 effective combination of these four segments is $171.5 \mathrm{~L} / \mathrm{s}$ (99.78\% probability of satisfying the

363 standards). A segmentation considering nine sectors has not been considered as the probability

364 of not satisfying the pressure requirements (87.13\%) is excessively high for this analysis.

\subsection{Calculation of number of PV arrays}

The number of PV panels has been calculated for the A and B scenarios (Pardo et. al.,

368 2018); the results are presented in Table 5.

369 In the B-scenarios, certain energy can be stored at peak hours of the day and released 370 when required for the pumps because a battery is available (Figure 5). For each of them, the

371 subunits are opened and closed to minimise the energy consumption (which involves irrigation 372 in the shortest period of time: 500 min for the $1 \mathrm{~B}$ and $3 \mathrm{~B}$ scenarios and 480 min for the $2 \mathrm{~B}$ 373 scenario). Subsequently, the energy audit is performed resulting in 420.51, 413.35 and 420.65 $374 \mathrm{kWh} /$ day per $1 \mathrm{~B}, 2 \mathrm{~B}$ and 3B scenarios respectively. The number of arrays is obtained as the 375 quotient between the energy required by the crops and the energy produced per PV array (1.21 $376 \mathrm{kWh}$ ). Finally, the numbers of PV panels for the scenarios analysed are 348, 342 and 348, 377 respectively (Table 5).

\section{4.5. Economic savings}

380 The monthly irrigation hours (input data) is added to the EPAnet model and the energy 381 consumed in Albamix (shaft work, $\mathrm{E}_{\mathrm{p}}(\mathrm{kWh})$; Table 6) is calculated. 
Moreover, the actual electric consumption considering that the pumps operate with an 383 efficiency of 0.75 is presented $\left(E_{l} \mathrm{kWh}\right)$ in Table 6 . The equivalent capital continuous discount 384 rate is considered at $r=2 \%$.

The carbon credits saved depend significantly on the energy sources, ; this is because each energy source emits different amounts of $\mathrm{CO}_{2}$ per $\mathrm{kWh}$ produced. In this approach, 554, 387865 and $1432 \mathrm{~g} / \mathrm{kWh}$ are produced if natural gas, oil and coal are the energy sources. These 388 figures have been retrieved from 'Water to Air Models', a tool developed by Pacific Institute 389 (Wolff et al., 2004). Certain other sources such as nuclear and hydro/solar/wind involve zero 390 greenhouse gas emissions. With regard to the source of energy, the energy mix in Spain (REE, 3912015 ) is reproduced; i.e. $11.4 \%$ of the total energy is produced by natural gas, $21.5 \%$ by coal 392 fired and $10.3 \%$ by oil fired (Table 6)¡Error! No se encuentra el origen de la referencia.. 393 Finally, the carbon credit price is 5 EUR/CC, as stated by the World Bank in its most recent 394 report (World Bank and Ecofys, 2017).

\subsection{Payback period for the three alternatives}

A-scenarios are cases where investments to purchase equipment are made only in the 398 present time. Therefore, the investment presented in Table 6 is identical to that previously 399 identified in Table 4. As aforementioned, the lifetime of the PV arrays is assumed to be 25 years. B-scenarios are cases where certain investments (purchase of batteries) are made in 401 future years (the batteries' lifetime is assumed to be five years, and the investments are 402 performed in years zero, five, 10, 15 and 20). $I_{0}$ and $I_{b a t}$ being values already presented (Table 403 5), the investment (in EUR) from the present time ( $t_{p}$ ) should be (numerical values in Table 6)

$$
I_{0}^{*}=I_{0}+I_{b a t}+I_{b a t} \cdot e^{-5 r}+I_{b a t} \cdot e^{-10 r}+I_{b a t} \cdot e^{-15 r}+I_{b a t} \cdot e^{-20 r}
$$


The annual savings (the energy consumption by the pumps; in Table 6: $C_{E N}=17307$ EUR

406 and $\left.C_{E N V}=596 \mathrm{EUR}\right)$ are obtained for the scenarios analysed. Finally, the net present value (NPV,

407 Eq. 4) and payback period (Eq. 5) are calculated either for the supply costs (considering only

408 the energy consumption savings) or for the entire economic costs (also considering the 409 environmental costs). The results are depicted in Table 7.

\section{4.7. Influence of equivalent continuous discount rate}

A sensitive parameter to be considered is the equivalent continuous discount rate. This

413 parameter represents each cash inflow/outflow that is discounted to its present value. This

414 value depends on the national banks in each country $(2.06 \%$ in USA; $-1.1 \%$ in UK; $1.48 \%$

415 Australia, FAO, 2017); moreover, it is a value that is not modifiable by water utility managers.

416 Its influence is illustrated in Table 8.

417 As can be demonstrated, the 2A-scenario is always the best alternative; however, its 418 results are highly influenced by this term. Low values of the equivalent discount rate involve 419 lower payback periods; to summarise, it is recommended that profits be re-invested to 420 purchase new equipment as the future savings will be marginally discounted, and the 421 investment is returned in a shorter period of time. On the contrary, a high discount rate applied 422 to cash flows occurring further along the time span may be used to reflect long-term debt. This 423 2A-scenario is ranged from 16.26 to 26.55 years, which is a high variation. As the life cycle of a 424 PV array is considered to be 25 years, it can be assumed to be an economically feasible 425 opportunity for utility managers. 
This work demonstrates that converting direct drive pumping systems supplied by 429 electricity grids into a standalone direct pumping photovoltaic system without considering the 430 effect of the type of segments described in the rigid rotation predetermined scheduled selected 431 for this operation can yield significant savings not fully exploited. Certain other parameters 432 such as the upper, lower and availability flowrate thresholds are described. These three terms 433 are infrastructure constraints (the irrigation network was dimensioned for 18-h irrigation) and 434 hydraulic constraints (water withdrawal from aquifers involves numerous limitations, 435 including technical and political limitations). Owing to these constraints, the energy demanded 436 by crops (as a result of the most efficient combination of hydrants opened and closed) does not 437 match the energy produced by PV panels. A cost analysis aimed at evaluating different 438 alternatives is proposed considering all the costs (current costs and future revenues) expressed 439 in monetary units at the present time (with the use of the equivalent continuous discount rate, $440 r$ ). This cost analysis returns the best alternative as the one with the lowest payback period. 441 With this structure, the effect of the variable costs linked to energy (energy and emissions costs) 442 and the effect of considering batteries for energy storage to protect the system against 443 emergency situations such as unfavourable weather has been determined. Between these two 444 effects, the first is expected; when the environmental costs with regard to emissions are 445 considered, these three alternatives are more competitive in these irrigation systems. The 446 segmentation that enables the delivery of a higher flowrate while maintaining the pressure 447 requirements become the most economical alternative (With these numbers, the 1A-scenario448 seven segments (Table 1), which permits the parallel operation of the three segments, 449 represent the best alternative).

450 The second (considering batteries) reveals that the short lifetime of the available 451 batteries indicate that the payback period is higher than those obtained without storage of 
452 electricity. As the payback period of several alternatives (five out of six) are lower than the PV

453 array lifetime, these alternatives are economically feasible (although in this case study, the 2A-

454 scenario is preferable over others). Moreover, these five alternatives present a scenario with

455 pumps supplied from in situ generated electricity, rather than from electricity grids; this can be

456 an alternative to prevent overload in electricity grids and to obtain electricity in isolated areas.

457 The key advantage of incorporating PV technology in irrigation is directly linked to their

458 environmental benefits: saving energy saves emissions as well. Although the economic price of

459 carbon credits does not represent large values, these environmental costs are taxes that can

460 effectively minimise the impact of carbon emissions on the environment; thereby, the

461 simulation becomes more realistic. Moreover, this project is completely framed in a future

462 scenario in which these utilities have followed the pathways for the transition to net-zero

463 energy consumption and greenhouse gas emissions.

464

465 6. ACKNOWLEDGMENTS

466 This work was supported by the research project "GESAEN" through the 2016 call of the 467 Vicerrectorado de Investigación, Desarrollo e Innovación de la Universidad de Alicante GRE$468 \quad 16-08$.

469

470 7. REFERENCES

471 Alexandratos, N.; Bruinsma, J. World agriculture towards 2030/2050 the 2012 revision

472 esa working 333 paper no. 12-03; Agricultural Development Economics Division. Food and

473 Agriculture Organization of 334 the United Nations (FAO): Rome, 2012. 
Amer, E.H. and Younes, M.A. (2006). "Estimating the monthly discharge of a photovoltaic 475 testing of a solar PV pump based drip system for orchards", Energy Conversion and 476 Management 47 (15):2092-2102

Betka, A. and Attali A. (2010). “Optimization of a photovoltaic pumping system based on 478 the optimal control theory" Solar Energy 84(7) (2010) 1273-1283Bloomberg, 2016. New 479 Energy Outlook 2016. Bloomberg New Energy Finance (BNEF) 480 〈https://www.bloomberg.com/company/new-energy-outlook/\#form〉, (accessed 09. 11.16). sobre el tipo impositivo aplicable a determinadas entregas de bienes y prestaciones de servicios 483 en el Impuesto sobre el Valor Añadido." BOE-A-2012-10534. Ministerio de Hacienda y 484 Administraciones Públicas. https://www.boe.es/eli/es/res/2012/08/02/(1) Cabrera E., Pardo, M.A., Cabrera E. Jr. and Arregui F.J.(2013) “Tap water costs and service sustainability, a close relationship". Water Resources Management. 27(1):239-253. doi:10.1007/s11269-012-0181-3 water pumping system technologies for irrigation and community drinking water supplies". Renewable and Sustainable Energy Reviews, 29 (2015) 1084-1099

De Soto, W., Klein, S.A. and Beckman, W.A. (2006)" "Improvement and validation of a 494 model for photovoltaic array performance”. Solar Energy, Vol 80, 78-88, 2006. 
Elkholy, M. M. and Fathy, A. (2016). “Optimization of a PV fed water pumping system

498 without storage based on teaching-learned-based optimization algorithm and artificial neural 499 network". Solar Energy 139 (2016) 199-212.

500 EC (2018). "Communication from the commission to the European Parliament, The 501 European council, the European economic and social committee, the committee of the regions 502 and the European investment bank. A Clean Planet for all A European strategic long-term vision 503 for a prosperous, modern, competitive and climate neutral economy". Brussels, 28.11.2018 $504 \operatorname{COM}(2018) 773$ final.

505 FAO (2017). “Tasa de interés real (\%), Fondo Monetario Internacional, Estadísticas 506 Financieras Internacionales y archivos de datos, a partir de datos del Banco Mundial sobre el el 507 deflactor del PIB."

508 https://datos.bancomundial.org/indicador/FR.INR.RINR?end=2017\&name_desc=true\&start=1961\&view=chart

509 Hadj Arab, A. Chenlob, F. Mukadamb, K. and Balenzategui, J.L. (1999), "Performance of 510 PV water pumping systems", Renewable Energy 18(1999) 191-204.

511 IEA (2016). "Water energy Nexus. Excerpt from the World energy Outlook 2016". 512 OECD/IEA, 2016 International Energy Agency. Paris Cedex 15, France. Available at: 513 https://www.iea.org/publications/freepublications/publication/WorldEnergyOutlook2016E $514 \quad$ x cerptWaterEnergyNexus.pdf

$515 \quad$ Kleiner, Y. and Rajani, B. 2001. Comprenhensive review of structural deterioration of 516 water mains:statistical methods. Urban Water 3(2001). 131-150.

517 McGovern, J. (2011).” Technical Note Friction Factor Diagrams for pipe Flow". Dublin 518 Institute of Technology, 2011. 
Narvarte, L., Fernández-Ramos, J., Martínez-Moreno, F. Carrasco, L.M., Almeida, R. H.,

520 Carrêlo, I. B. (2018). "Solutions for adapting photovoltaics to large power irrigation systems for

521 agriculture”. Sustainable Energy Technolo.Assess., 29, 119-130.

Nederstigt, J., Bom, G.J., 2014. Renewable energy for smallholder irrigation. A desk study

523

on the current state and future potential of using renewable energy sources for irrigation by

524 smallholder farmers, SNV

525

Pande, P.C.. Singh, A.K., Ansari, S, Vyas, S.K. and Dave, B.K. (2003). “Design development and testing of a solar PV pump based drip system for orchards". Renewable Energy, 28(3) 385$527 \quad 396$

Pardo, M. A., Manzano, J. and García-Marquez, D. (2018). "Energy Consumption

529 Optimization in Irrigation Networks Supplied by a Standalone Direct Pumping Photovoltaic 530 System". Sustainability, 201810, 4203. DOI: 10.3390/su10114203

Pardo, M.A., Riquelme, A., and Melgarejo, J. (2019). A tool for calculating energy audits in 532 water pressurized networks. Aims Environmental Science (accepted for publication). global agriculture: Scenarios and related impacts". Science of the Total Environment 409 535 (2011) 4206-4216. doi:10.1016/j.scitotenv.2011.07.019

Reca, J., Torrente, C., López-Luque, R. and Martínez, J. (2016). "Feasibility analysis of 537 standalone direct pumping photovoltaic system for irrigation in Mediterranean greenhouses". 538 Renewable Energy 85 (2016) 1143-1154. 
Replogle, J.A., Gordon, E., (2007). "Delivery and distribution systems". Design and

542 Operation of Farm Irrigation Systems, 2nd edition. American Society of Agricultural and 543 Biological Engineers. ISBN 1-892769-64-6

544 Rossman, L. A. (2000). EPANET 2: User's manual, U.S. Environmental Protection Agency, 545 Cincinnati.

546 Senol, R. (2012). "An analysis of solar energy and irrigation systems in Turkey”. Energy $547 \quad$ policy 47 (2012) 478-486.

548 Shamir U. and Howard C.D.D. 1979. Analytical approach to scheduling pipe replacement. 549 Journal of American Water Works Association, 71(5), 248-258.

550 Shiklomanov IA, Rodda JC. World water resources at the beginning of the 21st century. 551 Cambridge: Cambridge University Press; 2003.

552 Tarjuelo, J. M., Juan A. Rodriguez-Diaz, Ricardo Abadía , Emilio Camacho, Carmen 553 Rocamora, Miguel A. Moreno, ( 2015) "Efficient water and energy use in irrigation 554 modernization: Lessons from Spanish case studies". Agricultural Water Management. Volume 555 162, , Pages 67-77

556 Todde, G., Murgia, L., Deligios, P.A., Hogan, R., Carrelo, I., Moreira, M., Pazzona, A. Ledda, 557 L. and Narvarte, L. (2019). "Energy and environmental performances of hybrid photovoltaic 558 irrigation systems in Mediterranean intensive and super-intensive olive orchards". Science of 559 the total Environment 651 (2019). 2514-2523.DOI: 10.1016/j.scitotenv.2018.10.175.

560 Wolff, G., Gaur, S. and Winslow, M. (2004). “User Manual for the Pacific Institute Water to 561 Air Models". Pacific Institute for Studies in Development, Environment, and Security, 654 13th 562 Street, Preservation Park. Oakland, California 94612.

563 https://pacinst.org/wp-content/uploads/2013/02/water_to_air_manual3.pdf 
World Bank and Ecofys. (2017). “Carbon Pricing Watch 2017.” (May), Washington, DC:

565 World Bank. Doi: 10.1596/9781-4648-1129-6. License: Creative Commons Attribution CC BY

$566 \quad 3.0$ IGO

567 


\section{$569 \quad$ 8. LIST OF FIGURES}

570

571

572

573

574

575

576

577

578

579

580

581

582

583

584

585

586

587

588

589

590

591

592

593

594

595 596

Figure 1. Workflow for the process to prioritize alternatives

Figure 2. Net energy transferred to water per a single photovoltaic array.

Figure 3. Upper and Lower network flowrate threshold for Albamix Network (Infrastructure constraint).

Figure 4. Cumulative probability of meeting pressure requirement with regard to injected flow.

Figure 5. Energy required and available for $1 B$ scenario

\section{LIST OF TABLES}

\section{Table 1. Water requirement combination for 5, 7 and 10 segments}

Table 2. Monthly Irrigation time and water requirements.

Table 3. Data required for irradiance curves calculation.

Table 4. Number of segments which can work simultaneously for several scheduling. methods.

Table 5. Number of PV panels for the scenarios analysed

Table 6. Monthly operational and environmental costs in Albamix network

Table 7. Net present Values and Payback Periods.

Table 8. Payback Periods for different values of $r$-equivalent continuous discount rate-. 